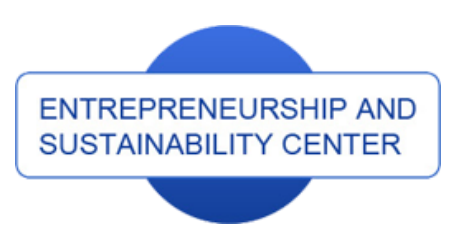

Publisher

http://jssidoi.org/esc/home

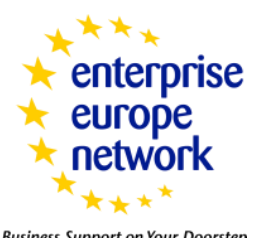

Business Support on Your Doorstep

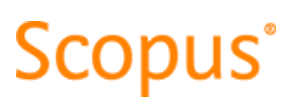

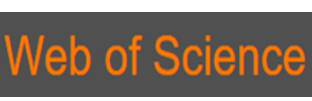

1) Clarivate

Analytics

\title{
RELEVANCE ANALYSIS OF FACTORS ENHANCING COACHING INTERACTIONS IN ORGANIZATIONS*
}

\author{
Angelina Rosha ${ }^{1}$, Natalja Lace ${ }^{2}$ \\ ${ }^{1,2}$ Faculty of Engineering Economics and Management, Riga Technical University \\ 6 Kalnciema Str., Riga, LV-1007, Latvia \\ E-mails. ${ }^{1}$ angelina.rosa@rtu.lv; ${ }^{2}$ natalja.lace@rtu.lv
}

Received 15 September 2017; accepted 10 January 2018; published 30 March 2018

\begin{abstract}
The article discusses the factors that are expected to enhance coaching interactions and reports the survey findings on the relevance of external and internal conditions to enhance coaching interactions in organizations. A particular focus of the literature review is to explore the factors ensuring a successful coaching interaction in organization. These characteristics are recognized as important predictors of coaching effectiveness. A questionnaire is designed to investigate the relevance of conditions that are likely to enhance coaching interactions in organisations. A list of conditions generally extracted from the literature review include external indirect conditions, external direct conditions, internal conditions at the level of organisation, internal conditions at the level of groups and internal conditions at individual (client's) level. The external indirect conditions comprise the reference to coaching in the context of EU documents. The external direct conditions are focused on the conditions that are expected to ensure the quality of service delivery. Internal conditions at the level of organisation are related to the features of organisational culture. The conditions at the level of groups have collaborative focus. Internal conditions at individual level are focused on the client. The survey was conducted from December 2014 to August 2015. Respondents were targeted from two groups: those who provide coaching service and those who receive this service. 75 coaches and coaching clients from Latvia and Lithuania took part in the survey. The obtained data is analyzed by using SPSS and conducting correspondence analysis to extract the most important factors. The analysis reveals the key factors under five categories that might be important in enhancing coaching interactions in organizations. The results obtained in the study are compared with the findings of theoretical and empirical literature review. The findings of the study are important for the further research in the field of organizational coaching to investigate the impact of factors on coaching delivery throughout organizational life cycle. Limitations. The data obtained by
\end{abstract}

\footnotetext{
* The paper has been elaborated within the project 5.2.2 "The Development of Innovation and Entrepreneurship in Latvia in Compliance with the Smart Specialization Strategy" of the National Research Programme 5.2 "Economic Transformation, Smart Growth, Governance and Legal Framework for the State and Society for Sustainable Development - A New Approach to the Creation of a Sustainable Learning Community (EKOSOC-LV)"
} 
using correspondence analysis can only be interpreted to make a general statement about the trends. The study is based on a limited number of respondents and therefore has certain statistic limitations.

Keywords: coaching interactions; relevance analysis; correspondence analysis; organizational performance

Reference to this paper should be made as follows: Rosha, A.; Lace, N. 2018. Relevance analysis of factors enhancing coaching interactions in organizations, Entrepreneurship and Sustainability Issues 5(3): 480-492. https://doi.org/10.9770/jesi.2018.5.3(5)

JEL Classifications: M10, M19, O15

\section{Introduction}

Nowadays organizational coaching has experienced a period of rapid growth. The number of organizations using coaching is increasing considerably; coaching is placed among facilitated activities in a wide range of contexts. There are a number of reasons to promote coaching in organizations. Coaching has a real practical impact and provides desirable and sustainable change for the benefit of both individuals and organisations (Cox et al., 2011). Moreover, coaching is a valuable tool that can trigger innovation capability. According to McCarthy (2014), the main use of coaching for innovation is to "foster a climate of innovation" in organization by facilitating the development of the innovation capability. The innovation capability is considered as the most crucial determinant of organization performance (Mone et al., 1998; Oganisjana et al., 2017; Tvaronavičienè, 2017, Rajnoha et al., 2017). Coaching also facilitates moving beyond innovative technologies from finding ideas and developing them to linking innovations to the company's strategy and the markets for what they have done (Kelley et al., 2005).

The scholars raise the question about the effectiveness of coaching interactions (Audet and Couteret, 2012). Despite the growing body of evidence-based research investigating the conditions for effective coaching outcomes, little is known regarding the research on factors that promote coaching throughout the organization. Identifying the determining factors that might contribute to coaching interactions is expected to enhance the design of coaching initiatives in organization.

Considering the peculiar issues of the use of coaching in Latvia and Lithuania, the paper aims to study the relevance of factors that are likely to enhance coaching interactions in organizations by analyzing the literature and conducting a survey among coach practitioners and coaching clients about the level of importance of conditions to promote coaching in organization. Building on the review of empirical research into coaching effectiveness in organizational context, the present study is guided by the following research question:

- What factors might contribute to the enhancement of coaching interactions in organization?

The paper begins with the literature review, then the used methodology is explained, lastly, the paper presents and discusses the survey findings.

\section{Literature review}

The analysis of the literature explores the key factors that influence coaching interactions from both the coach practitioner and coaching client perspective and associated with coaching effectiveness in organizational settings. The scholars (Bozer et al., 2013, Vidal-Salazar et al., 2012) attach importance to the effectiveness of coaching. They consider that coaching outcomes should be translated into organizational change and sustainability.

The first stage in the present literature review is to explore the essence of coaching in the context of organization. Coaching is generally defined as a support practice aims to enhance learning and development, often within a context of change (Caplan, 2003; Cox et al., 2011; Cox, 2013). Behavioural change within the organisational 
The International Journal

ENTREPRENEURSHIP AND SUSTAINABILITY ISSUES

ISSN 2345-0282 (online) http://jssidoi.org/jesi/

2018 Volume 5 Number 3 (March)

http://doi.org/10.9770/jesi.2018.5.3(5)

change opens a number of opportunities for coaching as a tool in implementing and sustaining change (Stober, 2008). Rosinski (2011) states that coaching can add value to organizational change facilitating management development beyond individual and team levels.

The role of coach is defined as a facilitator and catalyst (Audet and Couteret, 2012). Audet and Couteret (2012) argue that coaching is based on a close interpersonal relationship between those who provide coaching service (coaches) and those who consume coaching service (coaching clients). They highlighted that the relationship plays a crucial role in the effective coaching process. However, Audet and Couteret (2012) notify that the relationship might not be productive if the individual is not receptive to coaching and has negative perception of facilitative interaction. Coaching is mainly concerned with management development that encourages organisational growth and leads to sustainability (Bozer et al., 2013). The literature provides extensive evidence regarding the positive effect gained from coaching initiatives in organization. Smither et al. (2003) examined the effects of executive coaching. They provided the data on the positive impact of coaching on setting specific goals and "solicit ideas for improvement".

A particular focus of the literature review is to explore the factors ensuring a successful coaching interaction in organization. The obtained results are summarized in Table 1.

Table 1. Conditions likely to have influence on the effectiveness of coaching

\begin{tabular}{|c|c|}
\hline Scholars & Conditions \\
\hline Bozer G., Sarros J., Santora J. (2013) & $\begin{array}{l}\text { Coachee learning goal orientation } \\
\text { Coachee pre-training motivation } \\
\text { Coachee feedback receptivity }\end{array}$ \\
\hline Bozer G., Sarros J., Santora J. (2014) & $\begin{array}{l}\text { Coach's academic background in psychology } \\
\text { Coach credibility }\end{array}$ \\
\hline $\begin{array}{l}\text { Bozer G., Sarros J., Santora J. (2013). } \\
\text { de Haan E., Duckworth A., Birch D., Jones C. (2013) }\end{array}$ & Coachee developmental self-efficacy \\
\hline de Haan E., Duckworth A., Birch D., Jones C. (2013) & Personality of the client \\
\hline $\begin{array}{l}\text { de Haan E., Duckworth A., Birch D., Jones C. (2013) } \\
\text { Baron. L, Morin, L. (2009) }\end{array}$ & Coach-coachee relationship \\
\hline Baron. L, Morin, L. (2009) & Supervisory support \\
\hline Rekalde I., Landeta J., Albizu E. (2015). & $\begin{array}{l}\text { Coach's ability to generate trust } \\
\text { Coach's competence in communication skills, } \\
\text { Coachee's responsibility for his/her own development } \\
\text { Coachee's commitment to the process }\end{array}$ \\
\hline Smith I., Brummel, B. (2013) & $\begin{array}{l}\text { Executive involvement } \\
\text { Perceptions of developability } \\
\text { Individual development plans }\end{array}$ \\
\hline Audet, J, Couteret, P (2012) & $\begin{array}{l}\text { Entrepreneur's open attitude to change } \\
\text { Motivation to transfer }\end{array}$ \\
\hline
\end{tabular}

Source: constructed by the authors based on the literature review

de Haan et al. (2011) investigate the helpfulness of coaching interventions. They defined the factors that clients perceive as truly helpful in coaching, among them the ability of coach to employ appropriate techniques; the quality of relationship; the support system; the personality of the coach. Audet and Couteret (2012) direct their research towards investigating of "winning conditions" to have an impact on the success of coaching initiatives. 
These conditions embody client's positive attitude to change, receptiveness to outside help and willingness to learn and change as well as being receptive to coaching and being open to change. The crucial role in the establishment of relationship belongs to the coach. It is the coach's responsibility to establish credibility and create the atmosphere of a mutual trust. Moreover, coach needs to encourage the coachee in change process, persuade the client to accept this change, acquire relevant knowledge and skills and, as a result, change the behaviour (Audet and Couteret, 2012).

Bozer et al. (2013) explore under which conditions coaching is likely to be more beneficial for participants. They emphasize the role of coachee characteristics such as learning goal orientation, pre-training motivation, feedback receptivity, and developmental self-efficacy. These characteristics are recognized as important predictors of coaching effectiveness. Bozer et al. (2014) highlight the importance of coach's educational background and credibility for improving coaching effectiveness. Rekalde et al. (2015) examined the factors from the coach and coaching client perspective. They emphasize the importance for coach practitioners to be competent to establish mutual trust and have communication skills.

Smith and Brummel (2013) examined the impact of executive involvement in the development process, the influence of perceptions of competency developablity and the effects of creating a formal individual development plan. The results of their study prove that these specific components play a significant role in coaching interactions. Client involvement is an important prerequisite for promotion and successful implementation of coaching. The client is often considered ready when they (1) are willing to invest time and energy in the process, (2) do the work of development even when it becomes difficult and (3) take personal responsibility for transferring what is learned into action for change on the job These three components of involvement are critical to the success of an executive's development. (Smith and Brummel, 2013). Commitment to the relationship appears to be a major success factor and constitutes a prerequisite for coaching effectiveness (de Haan et al., 2013; Baron and Morin, 2009).

\section{Methodology}

The literature review was conducted to identify a range of factors and the survey approach was used to collect the data from coach practitioners and coaching recipients. The questionnaire was prepared to assess the relevance of a variety of factors placed in different categories. The questionnaire was pre-tested with coach practitioners to check and modify accordingly its content validity and terminology.

\section{Questionnaire for coaches and coaching clients}

The aim of the questionnaire is to investigate the relevance of conditions that are likely to enhance coaching interactions in organisations.

Sampling. Coach practitioners: sample is done from a list of coaches which is prepared preliminarily and is based on the open source database. The above mentioned sampling strategy is stipulated by the fact that coaching is not a profession in classic sense. In a traditional sense, recognition of coaching as a profession is in a long-term perspective. In the current state, coaching is mostly considered as a cross-disciplinary occupation (Gray, 2010) self-regulated by professional bodies, among which the following bodies are highlighted: International Coach Federation, European Mentoring and Coaching Council, Association for Coaching. Moreover, coaching is not the subject of governmental accreditation and professional license. As a consequence, it is nearly impossible to determine the total number of practitioners who provide coaching practice in Latvia and Lithuania. Therefore, for the purpose of the present survey, it was decided to use the open databases available on websites of coaching and training organizations in Latvia and Lithuania. Coaching recipients: sample is done from a set of people who use coaching service or are aware about coaching and have their opinion about coaching interactions. The population 
size for this group of respondents is practically not known as long as this target group is composed of entrepreneurs, business owners, management at all levels as well as specialists who represent any industry in Latvia and Lithuania.

Questionnaire design. The questionnaire consists of two sections designed to gather the information to answer the research question. The Section 1 of the questionnaire consists of closed multiple choice questions and is specially designed for coach practitioners and coaching recipients. Coaches are asked to identify their professional position. Taking into consideration that coaches can combine coaching practice and employment in other areas, they are asked to select all appropriate variants. The second question is focused on the professional qualifications in coaching. The coaches are able to select both academic qualifications, i.e. Master degree in coaching and / or Bachelor degree in coaching, and non-academic qualifications provided by both International Coaching Federation (ICF) and other coaching professional bodies. The third question indicates the period of professional engagement. Thus, the created profile of the respondents gives opportunity to compare the opinion of coaches with different professional positions, qualifications and engagement. Section 1 of the questionnaire for the coaching clients comprises four multiple choice questions. They are focused on professional position and engagement of the respondents. The section also contains two questions that enable to gather information about the size of the organizations and the industries where these organizations operate.

Section 2 of the questionnaire contains closed-ended importance questions. On a rating scale of 1 to 5 with 1 being "Not important" and 5 being "Extremely important, coaches and coaching clients are asked to rate the importance of the conditions that are likely to facilitate the promotion of coaching in organisations and thus, enhance coaching interaction. These questions enable to better understand what holds significance to the respondents. The respondents' answers also enable to make comparison and find agreement in the perception of the importance of conditions. A list of conditions is generally extracted from the literature review and includes external indirect conditions, external direct conditions, internal conditions at the level of organisation, internal conditions at the level of groups and internal conditions at individual (client's) level.

Piloting and modifying the questionnaire. A pilot test was developed to examine content validity of the questionnaire in regards to relevance of conditions and clarity of language. Content validity, as one of the most important validation in developing new questionnaires, has become a central issue of the piloting. The Questionnaire piloting helps find the best wording and the best balance between the amount of information requested from individual respondents. The comments and suggestions of the experts in coaching are analyzed and considered. After piloting, the questionnaire was reworked.

Data processing. The obtained data is analyzed by using Statistical Package for the Social Sciences (SPSS) and conducting correspondence analysis. As an exploratory data technique, correspondent analysis aims to analyze categories of external and internal conditions for promoting coaching in organizations and extract the most important factors. Correspondence analysis is widely used in such areas as marketing and ecology. Some scholars (Doey and Kurta, 2011) consider that correspondence analysis can be applied in the other research areas where categorical variable need to be analyzed. This analysis extracts the most important data and use the graphical map to visualize the associations among variables. However, some limitations should be taken into consideration. This analysis interprets the strength of trends within the data. The distance between row points and column points shows the relativities and only general statements are made about observed trends.

\section{Results and discussion}

Categorization of factors identified in the literature review. 
27 conditions fall under five categories. The choice of conditions is mostly guided by the findings in the literature on organizational coaching. The factors cannot be considered as exhaustive and all-inclusive.

External indirect conditions are expected to affect indirectly the promotion of coaching in organisation. They include:

8-1 Reference to coaching in the context of EU documents

8-2 Recommendations to integrate coaching in training programmes

8-3 Innovations in business, psychology, education, etc. that facilitate developing coaching theory

The choice of these conditions was determined by the following.

Several high-level EU initiatives, such as Entrepreneurship 2020 Action Plan, Open Innovation 2.0 (OI2), and Horizon 2020 as well as CoachCom2020 project draw attention to coaching. Coaching is proposed to apply together with management training and networking to support new businesses in crucial phases of their lifecycle and help them grow.

Innovations in business, psychology, education trigger the development of new approaches, techniques and models in coaching. These technologies are aimed at improving the effectiveness of coaching focusing on the reliability and sustainability of coaching outcomes. Effective coaching outcomes, which are the result of the innovative ideas in different areas, provide a strong argument in promotion of coaching in organisations.

External direct conditions are focused on all that might be associated with coaching service from the dissemination of good practices to the personality of coaches. The conditions were involved on the basis of literature analysis and the suggestions that were made by the experts during the questionnaire piloting. The following variables constitute external direct conditions:

9-1 Disseminating best practices in coaching

9-2 Establishing professional standards for coaches

9-3 Providing coaching industry research

9-4 Cooperation of coaching professional associations with other professional and government organizations

9-5 The system of professional supervision to oversee the work of the coach

9-6 Education and continuing training for coaches

9-7 Coach's ability to employ the skills related to the core coaching competences

9-8 Coach's awareness of business processes

The following arguments were taken into account in selection of external direct conditions. Professionalization of coaching is a complex and sensitive topic. It is a fact that only well-educated, skilled, credentialed coaches can ensure the environment that will forward coaching in organisations. However, coach training programs vary considerably, from short online courses and weekend workshops, to a three-year academic masters-level program. Establishing professional standards for coaches will allow having clearer picture of the service provided by coaches. Much work is done by the professional bodies to recognize coaching as a self-regulated profession. However, some scholars (Bachkirova, 2014) suggest that coaching presently is a market-regulated practice.

It is important to develop science-based coaching practices conducting research studies in the field of coaching. Partnership between coaching professional associations and other professional organizations and government agencies expands consensus and supports community building and networking.

The system of professional supervision provides constructive feedback. 'Supervision in coaching can be broadly understood as being as a structured process for coaches designed to help coaches attend to improving the quality 
of the coaching, to grow their coaching capabilities and support themselves and their practice with the help of a coaching supervisor' (Grant, 2012).

The ability to employ various techniques effectively and at the right moment may be considered as one of the components of quality. This statement was proved by the study conducted by de Haan et al. (2011). They concluded that a broad range of techniques are deemed helpful. However, it was suggested that general factors common to all good coaching (such as the quality of the relationship or "working alliance" between coach and client, the support system of the client, the personality of the coach, client expectations) can predict helpfulness of coaching, rather than specific behaviors, techniques, or models of coaching (de Haan et al., 2011).

Internal conditions are presented at three levels: organisational, group and individual respectively. Internal conditions at the level of organisation:

10-1 Goal-oriented organisational culture

10-2 Top management support for learning and development

10-3 Motivation to learn and acquire new skills

10-4 Requiring new skills acquisition because of organisational change

10-5 The opportunity to apply the knowledge and skills acquired in the training to the job

10-6 Relationship of trust and openness among the members of organisation

Coaching can help organisations identify the mechanisms to achieve growth that is best suited to their unique circumstances. Internal conditions at the level of organisation are related to the features of organisational culture such as goals orientation, support orientation, learning culture, relationship of mutual trust and openness, a culture of effective feedback. These components of culture create a favorable environment for the development of coaching culture within the organisation.

\section{Internal conditions at the level of groups:}

11-1 High cohesion and good communication within team

11-2 Collaborative planning

11-3 Making decision in groups / teams

11-4 Employees learning and development within the groups / teams

Teams are a key structural component in most businesses today (Peters and Carr, 2013). That is why the conditions at the level of groups are likely to have significant impact on the promotion of coaching in the groups in particular and in organization in general. Team coaching is distinct from individual coaching because in team coaching, the team as a whole is the client and collective performance is the goal, versus the individual focus of one-on-one coaching (Peters and Carr, 2013). The aim of team coaching is to support team members to structure their work and conversations to communicate well, make decisions and ensure the achievement of the optimal result through a joint effort of the group. Team coaching can also be the integral part of team learning. Therefore, the conditions that were selected for the questionnaire have collaborative focus.

\section{Internal conditions at individual (client's) level:}

12-1 Client's positive attitude to change

12-2 Being receptive to help

12-3 Client's willingness to learn and change

12-4 Client's feedback receptivity

12-5 Client's willingness to invest time and energy in coaching process

12-6 Client's involvement in the coaching process 
Coaching is also rather beneficial for individuals. Changes make employees become more responsible for their personal and professional development. They need to develop certain skills to better manage themselves by improving their own performance through their own efforts and will (Stokes and Jolly, 2011). Internal conditions at individual level are focused on the client. Client engagement plays significant role in the success of coaching and extends coaching implementation in organisation.

The survey. The survey was conducted from December 2014 to August 2015. Totally 75 respondents from Latvia and Lithuania have participated. Almost $70 \%$ of coaches who did respond to the survey reported that they have graduated from the International Coach Federation approved or accredited coach training programs, and a little more than $70 \%$ of respondents positioned themselves as executive coaches. $40 \%$ of coaches have practiced in coaching for $3-5$ years and $29 \%$ of coaches have been in business for $6-9$ years.

The obtained data are analyzed by using the Statistical Package for the Social Sciences (SPSS) and conducting correspondence analysis. Two dimensions: number of question and score are extracted. The results are presented in the form of a biplot.

Three types of conditions are analyzed under external indirect category (see Fig.1). These conditions may have an indirect impact on promotion of coaching in organization. A correspondence map demonstrates that two external indirect conditions, namely, the integration of coaching in training programmes (Q 8-2) and innovations in business, psychology, education, etc. that facilitate developing coaching theory (Q 8-3) are perceived by the respondents as more important conditions than reference to coaching in the context of EU documents (Q 8-1). Thus, Q 8-2 and Q 8-3 conditions are taken into account for the further analysis.

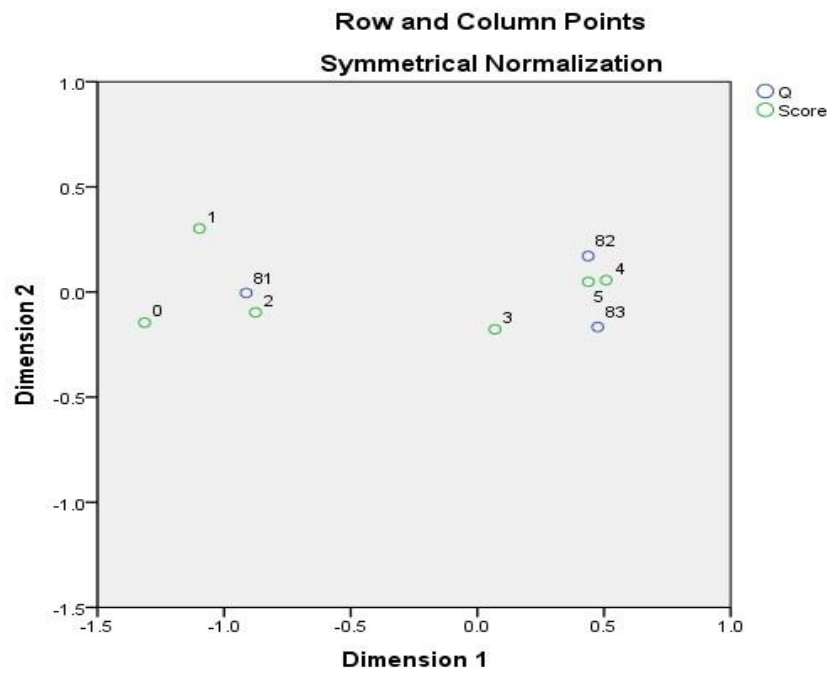

Fig.1. A biplot displaying external indirect conditions and how they relate to the level of importance Source: constructed by the authors

Under the external direct conditions category, the conditions referring to the provision of coaching service are analyzed (see Fig.2). Three out of eight external direct conditions are placed at a close distance from point "5". 
They are the following conditions: disseminating best practices in coaching (Q 9-1), education and continuing training for coaches (Q 9-6), and coach's ability to employ the skills related to the core coaching competences (Q 9-7). This result leads to the conclusion than they are the conditions that respondents consider important. The literature provides the empirical support to these findings. Bozer et al. prove that coaches' academic background and credibility positively relate to coaching effectiveness.

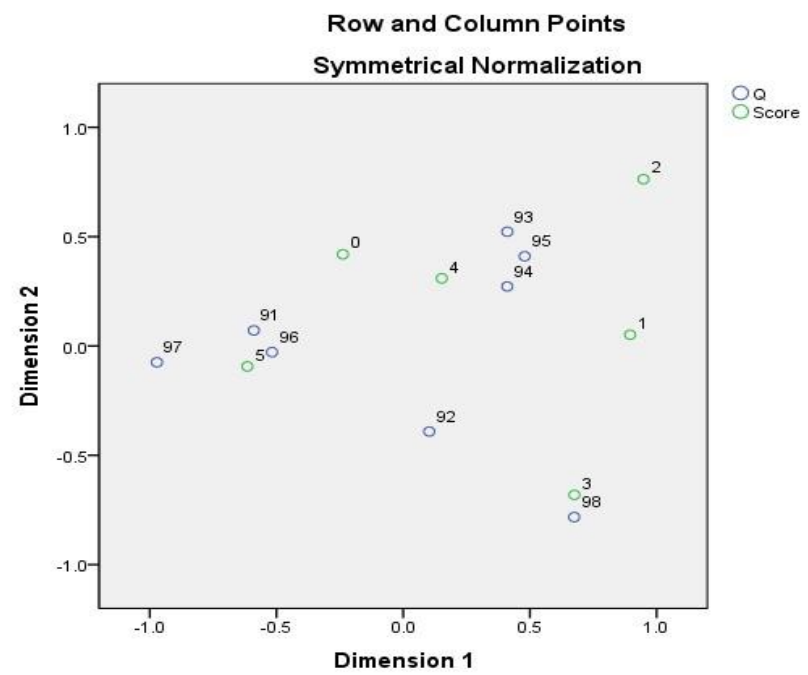

Fig. 2. A biplot displaying external direct conditions and how they relate to the level of importance Source: constructed by the authors

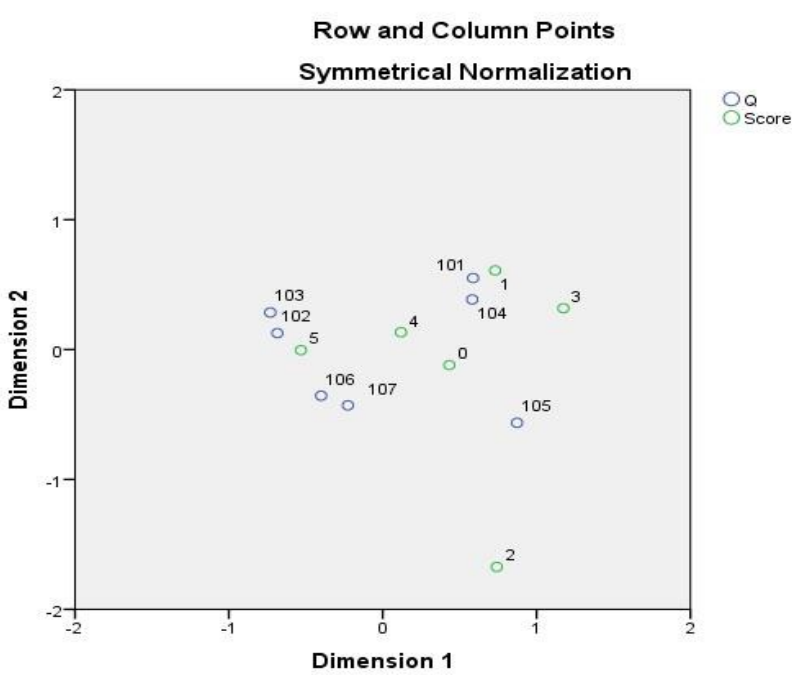

Fig.3. A biplot displaying internal conditions at the level of organization and how they relate to the level of importance Source: constructed by the authors

Internal conditions are analyzed under three categories: organizational level, group level and individuals' level. Internal conditions at the level of organization are culture-oriented. The biplot demonstrates the distribution of points (see Fig.3). The point Q 10-2 is in the nearest position to the point "5". Therefore, the top management support for learning and development is considered by the respondents as the most important internal condition. This result is in the agreement with the empirical study made by Baron and Morin (2009). They argue that supervisor support might "reinforce the perceived value of the process and encourage the coachee's efforts to develop." Two more points Q 10-3 and Q 10-6 are also in close position to the point " 5 ". Thus, motivation to learn and acquire new skills (Q 10-3) and the opportunity to apply the knowledge and skills acquired in the training to the job (Q10-6) are also conditions that are perceived by the respondents as important.

Internal conditions at the level of groups have collaborative focus. The results demonstrates the condition Q 11-4 (employees learning and development within the groups / teams) is placed in the shortest distance from point " 5 " (see Fig.4). Respondents consider this condition as the most important.

Internal conditions at individual level are focused on the recipient of coaching. The point Q12-6 is in the nearest position to point "5" (see Fig.5). This result demonstrates that "client's involvement in the coaching process" is considered as the most important condition. The points of conditions Q 12-5 (client's willingness to invest time and energy in coaching process) and Q 12-3 (client's willingness to learn and change) are closely placed to point " 5 " and considered the important for respondents' conditions. 


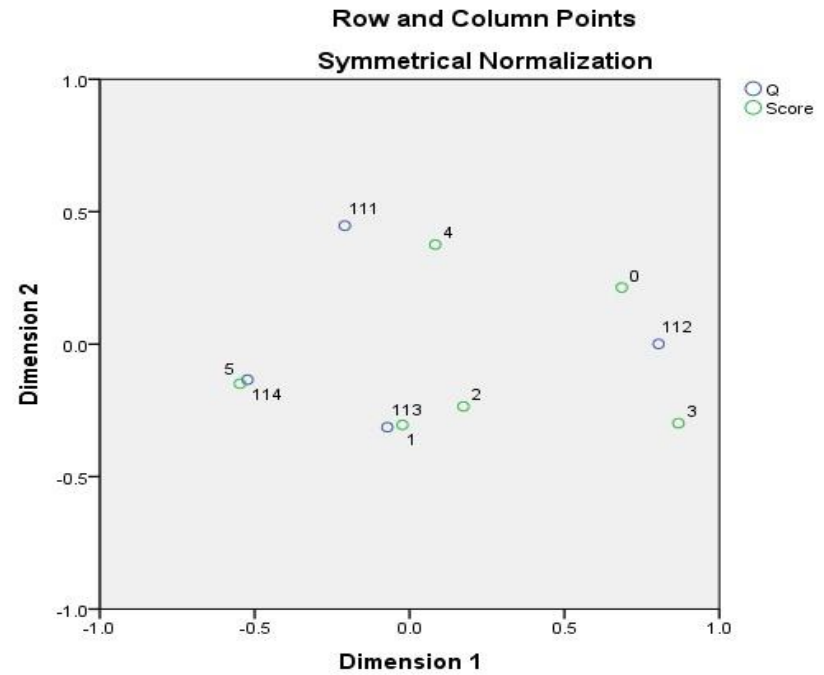

Fig. 4. A biplot displaying internal conditions at the level of groups and how they relate to the level of importance Source: constructed by the authors

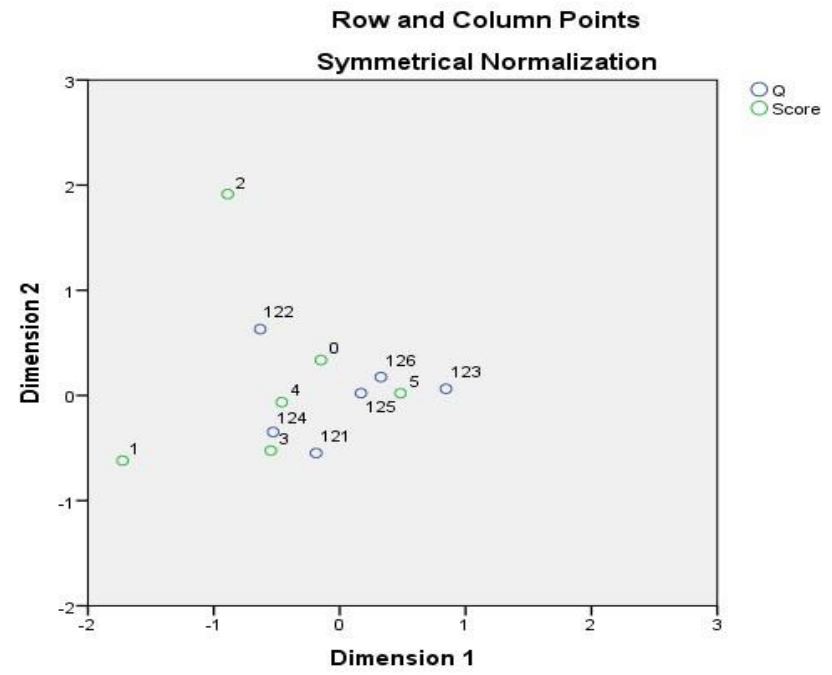

Fig.5. A biplot displaying internal conditions at individual level and how they relate to the level of importance Source: constructed by the authors

Consolidated Table 2 presents the generalization of factors that are considered important to enhance coaching interaction in organization.

Table 2. Factors Enhancing Coaching Interactions in Organizations

\begin{tabular}{|l|l|}
\hline \multirow{2}{*}{ External factors of indirect effect } & Innovations in the related fields of knowledge \\
\cline { 2 - 2 } & Guidance regarding integrating coaching throughout the learning process \\
\hline \multirow{3}{*}{ External factors of direct effect } & Benchmarking of coaching best practices \\
\cline { 2 - 2 } & Continuing professional development for coaches \\
\cline { 2 - 2 } & Demonstrating confidence in core coaching competencies \\
\hline \multirow{2}{*}{$\begin{array}{l}\text { Internal factors at the level of } \\
\text { organisation }\end{array}$} & Support of executives \\
\cline { 2 - 2 } & Motivation for acquiring new skills \\
\cline { 2 - 2 } $\begin{array}{l}\text { Internal factors at the level of } \\
\text { groups }\end{array}$ & A culture of trust and openness \\
\hline \multirow{2}{*}{$\begin{array}{l}\text { Internal factors at individual (client's) } \\
\text { level }\end{array}$} & Individual's commitment to change \\
\cline { 2 - 2 } & Individual's readiness to invest time and energy in coaching \\
\cline { 2 - 2 } & Individual's engagement in the coaching process \\
\hline
\end{tabular}

Source: constructed by the authors

The results of this study indicate that the factors mostly related to learning and development at different levels, i.e. organizational, group and individual, are considered the most important. These factors are expected to play a meaningful role in the effectiveness of coaching engagements. The findings have empirical support made by Bozer et al. (2013), Rekalde et al. (2015), Smith and Brummel (2013). 
The International Journal

ENTREPRENEURSHIP AND SUSTAINABILITY ISSUES

ISSN 2345-0282 (online) http://jssidoi.org/jesi/

2018 Volume 5 Number 3 (March)

http://doi.org/10.9770/jesi.2018.5.3(5)

\section{Conclusions}

The aim of the study was to explore the relevance of the conditions that can enhance coaching interactions in organization and constitute a prerequisite for coaching effectiveness.

The present paper provides the analysis of factors based on the literature review and survey of coach practitioners and coaching clients. Correspondence analysis as a statistical technique provides the graphical maps that facilitate visualization of the associations between the conditions that are expected to contribute to the effectiveness of coaching interactions and the level of importance of these conditions as it is perceived by survey respondents.

The results of this study have practical implication. The findings of the study are important for the further research in the field of organizational coaching to investigate the impact of factors on coaching delivery throughout organizational life cycle.

Limitations. The data obtained by using correspondence analysis can only be interpreted to make a general statement about the trends. The study is based on a limited number of respondents and therefore has certain statistic limitations.

\section{References}

Audet, J.; \& Couteret, P. 2012. Coaching the entrepreneur: features and success factors, Journal of Small Business and Enterprise Development 19(3): 515-531. https://doi.org/10.1108/14626001211250207

Bachkirova, T. 2014. Revising the role of caching supervision, Организационная психология 4(1): 125-128.

Baron, L.; \& Morin, L. 2009. The Coach-Coachee Relationship in Executive Coaching: A Field Study, Human Resource Development Quarterly 20(1): 85 - 105. https://doi.org/10.1002/hrdq.20009

Bozer, G.; Sarros, J.; \& Santora, J. 2014. Academic background and credibility in executive coaching effectiveness, Personnel Review 43(6): 881-897. http://dx.doi.org/10.1108/PR-10-2013-0171

Bozer, G.; Sarros, J.; \& Santora, J. 2013. The role of coachee characteristics in executive coaching for effective sustainability, Journal of Management Development 32(3): 277-294. http://doi.org/10.1108/02621711311318319

Caplan, J. 2003. Coaching for the Future: How smart companies use coaching and mentoring. London: Published by Chartered Institute of Personal and Development

Cox, E. 2013. Coaching Understood. A Pragmatic Inquiry into the Coaching Process. First Edition. London: Published by Sage Publications Ltd.

Cox, E.; Bachkirova, T.; \& Clutterbuck, D. 2011. The Complete Handbook of Coaching. London: Published by Sage Publications Ltd.

de Haan, E.; Culpin, V.; \& Curd, J. 2011. Executive coaching in practice: what determines helpfulness for clients of coaching? Personnel Review 40(1): 24-44. https://doi.org/10.1108/00483481111095500

de Haan, E.; Duckworth, A.; Birch, D.; \& Jones, C. 2013. Executive coaching outcome research: The contribution of common factors such as relationship, personality match, and self-efficacy, Consulting Psychology Journal Practice and Research 65(1): 4057. http://dx.doi.org/10.1037/a0031635

Doey, L.; \& Kurta, J. 2011. Correspondence Analysis applied to psychological research, Quantitative Methods for Psychology, 7(1): 5-14. https://doi.org/10.20982/tqmp.07.1.p005 
The International Journal

ENTREPRENEURSHIP AND SUSTAINABILITY ISSUES

ISSN 2345-0282 (online) http://jssidoi.org/jesi/

2018 Volume 5 Number 3 (March)

http://doi.org/10.9770/jesi.2018.5.3(5)

Grant, A. 2012. Australian Coaches' Views on Coaching Supervision: A Study with Implications for Australian Coach Education, Training and Practice, International Journal of Evidence Based Coaching and Mentoring 10(2): 17-33.

Grey, B. 2010. Towards the lifelong skills and business development of coaches: An integrated model of supervision and mentoring, Coaching An International Journal of Theory Research and Practice Research and Practice 3(1): 60-72. https://doi.org/10.1080/17521880903559705

Kelley, D.; Neck, H.M.; O'Connor, G.C.; \& Paulson, A. 2005. Corporate entrepreneurship through radical innovation: key organization and innovative level mechanisms, in Elfring, T. (Ed.). Corporate entrepreneurship and venturing. Springer US, 23-48. Retrieved from http://www.untag-

smd.ac.id/files/Perpustakaan_Digital_1/ENTREPRENEURSHIP\%20Corporate\%20Entrepreneurship\%20and\%20Venturing.pdf

McCarthy, G. 2014. Coaching and Mentoring for Business. London: Published by SAGE Publications Ltd.

Mone, M.; McKinley, W.; \& Barker, V. 1998. Organizational Decline and Innovation: A Contingency Framework, The Academy of Management Review 23 (1): 115 -132. http://dx.doi.org/10.5465/AMR.1998.192965

Oganisjana, K.; Svirina, A.; Surikova, S.; Grīnberga-Zālīte, G.; Kozlovskis, K. 2017. Engaging universities in social innovation research for understanding sustainability issues, Entrepreneurship and Sustainability Issues 5(1): 9-22. https://doi.org/10.9770/jesi.2017.5.1(1)

Peters, J.; \& Carr, C. 2013. Team effectiveness and team coaching literature review, Coaching: An International Journal of Theory, Research and Practice 6(2): 116-136. http://dx.doi.org/10.1080/17521882.2013.798669

Rajnoha, R.; Korauš, A.; Dobrovič, J. 2017. Information systems for sustainable performance of organizations, Journal of Security and Sustainability Issues 7(1): 167-179. https://doi.org/10.9770/jssi.2017.7.1(14)

Rekalde I.; Landeta, J.; \& Albizu E. 2015. Determining factors in the effectiveness of executive coaching as a management development tool, Management Decision 53(8): 1677-1697. https://doi.org/10.1108/MD-12-2014-0666

Rosinski, P. 2011. Global Coaching for Organizational Development, International Journal of Coaching in Organizations 30 (8): $49-66$.

Smith, I.; \& Brummel, B. 2013. Investigating the role of the active ingredients in executive coaching, Coaching: An International Journal of Theory, Research and Practice 6 (1): 57 -71. https://doi.org/10.1080/17521882.2012.758649

Smither, J.; London, M.; Flaut, R.; Vargas, Y.; \& Kucine, I. 2003. Can working with an executive coach improve multisource feedback ratings over time? A quasi-experimental field study, Personnel Psychology 56 (1): 24 - 44.

Stober, D. 2008. Making it stick: coaching as a tool for organizational change, Coaching: An International Journal of Theory, Research and Practice 1(1):71-80. https://doi.org/10.1080/17521880801905950

Stokes, J.; \& Jolly, R. 2011. Executive and Leadership Coaching. In E. Cox, T. Bachkirova, \& D. Clutterbuck (Eds.), The Complete Handbook of Coaching SAGE Publications Ltd. 245-257.

Tvaronavičienè, M.. 2017. Clusters, innovations and energy efficiency: if relantionship could be traced, Marketing and Management of Innovations 2: 382 - 391 https://doi.org/10.21272/mmi.2017.2-35

Vidal-Salazar, M.; Ferro'n-V1'lchez, V.; \& Cordo'n-Pozo, E. 2012. Coaching: an effective practice for business competitiveness Competitiveness Review: An International Business Journal 22(5): 423-433. https://doi.org/10.1108/10595421211266302 
The International Journal

ENTREPRENEURSHIP AND SUSTAINABILITY ISSUES

ISSN 2345-0282 (online) http://jssidoi.org/jesi/

2018 Volume 5 Number 3 (March)

http://doi.org/10.9770/jesi.2018.5.3(5)

\section{Aknowledgements}

The paper has been elaborated within the project 5.2.2 "The Development of Innovation and Entrepreneurship in Latvia in Compliance with the Smart Specialization Strategy" of the National Research Programme 5.2 "Economic Transformation, Smart Growth, Governance and Legal Framework for the State and Society for Sustainable Development - A New Approach to the Creation of a Sustainable Learning Community (EKOSOC-LV)"

Mg Sc Angelina ROSHA is a lectuter at Riga Technical University (RTU). She holds a Master Degree in Humanities (2005) and has a Diploma in Pedagogy (1986). The overall pedagogical experience in HEIs is more that 20 years; she also had experience in entrepreneurship for 5 years. She is an author and co-author of more that 10 scientific papers on coaching, organizational coaching. Since 2015 she has been participating in the project 5.2.2 „The Development of Innovation and Entrepreneurship in Latvia in Compliance with the Smart Specialization Strategy" within the National Research Program 5.2 EKOSOC-LV (2014 - 2017). Areas of research interests: coaching for innovation, organizational coaching, leadership and human resource development.

ORCID ID: 0000-0001-8272-8203

Dr. Natalja LACE is a professor at Riga Technical University (RTU). She graduated from RTU (former Riga Polytechnic Institute), Faculty of Engineering Economics in 1982 with the diploma of engineer-economist. The doctoral thesis (1990) was focused on alternative choice of engineering decision making. Her pedagogic activities encompass bachelor, master and doctoral programmes: lecturing, supervising and reviewing bachelor, master and PhD theses. Natalja Lace is the Head of the Department of Corporate Finance and Economics and the Director of Master program "Business Finance" at Riga Technical University Faculty of Engineering Economics and Management. She is a Member of the Editorial Board of several academic journals and an expert of the Latvian Council of Science. Professor Natalja Lace is an author, co-author and editor of more than 200 scientific papers and books. She is involved in executing of research projects sponsored by the Latvian Government and Scientific Council of Republic of Latvia. Her research interests are focused on critical success factors of small and medium sized enterprises and innovation as well as financial aspects of business.

ORCID ID: 0000-0003-1154-839X

Register for an ORCID ID:

https://orcid.org/register

Copyright (C) 2018 by author(s) and VsI Entrepreneurship and Sustainability Center

This work is licensed under the Creative Commons Attribution International License (CC BY).

http://creativecommons.org/licenses/by/4.0/

c) (i) Open Access 